\title{
Mechanical Behavior of Interface between Composite Geomembrane and Permeable Cushion Material
}

\author{
Haimin Wu, ${ }^{1}$ Yiming Shu, ${ }^{1,2}$ Linjun Dai, ${ }^{2}$ and Zhaoming Teng ${ }^{2}$ \\ ${ }^{1}$ State Key Laboratory of Hydrology-Water Resources and Hydraulic Engineering, Hohai University, Nanjing 210098, China \\ ${ }^{2}$ College of Water Conservancy and Hydropower Engineering, Hohai University, Nanjing 210098, China
}

Correspondence should be addressed to Haimin Wu; wuhaimin@hhu.edu.cn

Received 28 July 2014; Accepted 26 September 2014; Published 22 October 2014

Academic Editor: Mohd Sapuan

Copyright (C) 2014 Haimin Wu et al. This is an open access article distributed under the Creative Commons Attribution License, which permits unrestricted use, distribution, and reproduction in any medium, provided the original work is properly cited.

An accurate description of composite geomembrane-cushion interface behavior is of great importance for stress-deformation analysis and stability assessment of geomembrane surface barrier of rock-fill dam. A series of direct shear tests were conducted to investigate the friction behaviors of interfaces between composite geomembrane and two different permeable cushion materials (crushed stones and polyurethane mixed crushed stones). The shear stress-displacement relationships of the two interfaces show different characteristics and were described by the nonlinear-elastic model and nonlinear-elastic perfectly plastic model, respectively. Then the two models were implemented into the Fast Lagrangian Analysis of Continua in Three Dimensions (FLAC ${ }^{3 \mathrm{D}}$ ) procedure correctly. By verification of a numerical example, numerical calculation results showed a good agreement with the theoretical solutions and test results.

\section{Introduction}

Due to the advantages of strong ability to adapt differential deformation, short construction period, low cost, field preservation, low carbon, and environment protection, geomembranes have increasingly replaced traditional barrier materials such as compacted clay, cement concrete, asphalt concrete, or grouting as watertightness of earth and rock-fill dam. By the year of 2010, there have been 167 large embankment dams that had chosen geomembranes as their barrier systems according to the International Commission on Large Dams (ICOLD) database [1]. With the rapid construction of water conservancy and hydropower engineering, more and more dams have to be constructed on the thick pervious foundation in China. Due to its strong ability to adapt differential deformation, geomembrane surface barrier systems become the preferred solution for the watertightness of high rock-fill dam on thick pervious foundation [2].

Geomembrane surface barriers are commonly comprised by three layers, namely, basal cushion layer, geomembrane barrier, and protection cover layer. In Chinese design specification for rolled earth-rock-fill dam, the geomembrane barrier is usually used with composite geomembrane (CGM) compounded by two layers of needle punched nonwoven geotextiles and a layer of high density polyethylene (HDPE) or polyvinyl chloride (PVC) geomembrane [3].

There are generally two kinds of traditional permeable materials that can be used as cushion layer for geomembrane surface barrier, namely, gravel materials and porous concrete. For high rock-fill dam with a steep dam slope, gravel materials cushion can hardly maintain its stability. Because of the inability to resist flexural deformation of the surface of dam slope, the brittle porous concrete may yield bending failure and develop into cracks. That would pose a threat to the safety of geomembrane under long-term loading of high water pressure.

Polyurethane (PUR) mixed crushed stone is a new elastic porous material casted by polyurethane adhesive mixed crushed stones. Due to the higher bending strength, excellent toughness, and permeability, it was used as the basal cushion layer of geomembrane in surface barrier of high rock-fill dam on thick pervious foundation [4]. In actual working condition, flexural deformations of the surface of dam slope resulted from self-weight and high water pressure loads may induce shear displacement along geomembrane-cushion interface. The shear displacement can mobilize shear stress 


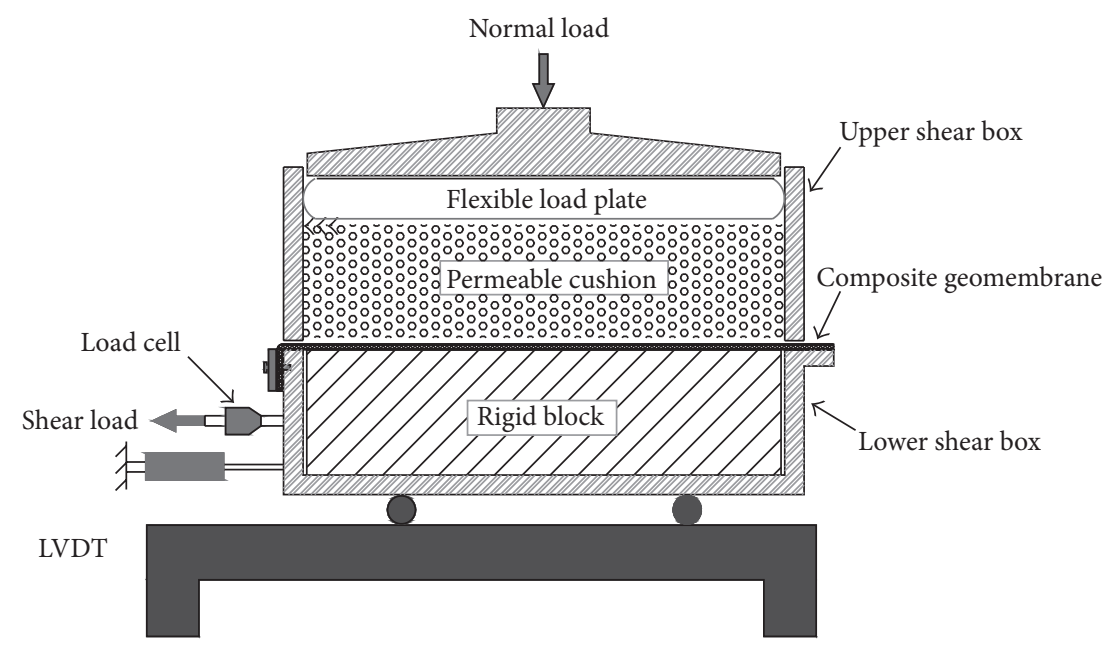

FIGURE 1: Schematic diagram of interface shear apparatus.

on the interface between geomembrane and cushion. And the low shearing strength on the interface between geomembrane and cushion materials may increase the tensile force of geomembrane and cause sliding failure of the whole barrier systems [5].

The mechanical behavior of geomembrane-cushion interface is the critical issue for deformation analysis and stability assessment of geomembrane surfaced barrier of high rock-fill dam. For CGM-cushion interface, the essence is the frictional behavior between needle punched nonwoven geotextile and cushion materials. Many researches on interface behaviors between geotextile and different soil materials have been reported during the last decade. For example, research involving the interface between geotextile and cohesive soil can be found in several literatures [6-8]. Studies on interface behaviors between geotextile and different sands have been reported by Lee and Manjunath [9] and Anubhav and Basudhar [10]. G. Zhang and J.-M. Zhang [11] and G. Zhang et al. [12] investigated the monotonic and cyclic behaviors of interface between geotextile and gravelly soil by laboratory test and numerical modeling. It can be seen that the research works mainly focus on interfaces between geotextile and different soils and sands in reinforcement structures. The interface between a geotextile and gravel materials with a grain size larger than that of soil and sand had not been investigated thoroughly. The research on interface between CGM and permeable cushions of barriers on slope had rarely been reported. Therefore, further study should be conducted on the friction behaviors of the interfaces between CGM and cushions materials.

The objectives of this study are to obtain shear strength and shear stress-displacement response of CGM-cushion interface by direct shear test and numerical modeling. The characteristics of interface shear strength and shear stressdisplacement relationship observed from test results are reported. Based on the experimental observations, the nonlinear-elastic model and nonlinear-elastic perfect-plastic model are applied to describe the interface stress-displacement relationships of CGM with crushed stones and PUR mixed crushed stones, respectively. Finally, the two interface models are incorporated into the Geogrid element of FLAC ${ }^{3 \mathrm{D}}$ procedure to predict the mechanical behaviors of two interfaces.

\section{Direct Shear Tests of Interfaces}

2.1. Direct Shear Apparatus. The size of shear box for direct shear apparatus has an effect on the shear strength at geosynthetic-soil interface. By contrasting the test results with different size of shear box, C. Hsieh and M.-W. Hsieh [13] recommended that a minimum dimension of $300 \times 300 \mathrm{~mm}$ direct shear box should be used. The similar regulations are also required in the ASTM D5321 [14]. In this study, a largescale direct shear machine was employed in shear tests. The schematic view of the apparatus is shown in Figure 1. The apparatus comprises a $300 \mathrm{~mm}$ square top box and a $300 \times$ $350 \mathrm{~mm}$ rectangular lower box. It has a maximum shear displacement of $50 \mathrm{~mm}$ with no loss in area of shear plane during shearing test.

The load plate rigidity in the normal direction of upper shear box can also influence the test results. The results of the study conducted by C. Hsieh and M.-W. Hsieh [13] indicated that the use of conventional rigid load plate in direct shear test resulted in a concave pressure distribution at the shearing plane. It was observed that using flexible load plate showed a better reproducibility of test data than using rigid load plate. So in order to apply a uniform flexible normal pressure on the interface, a $2 \mathrm{~cm}$ thick soft silicon plate, placed at the bottom of rigid load plate, was used to form a flexible load plate in the upper shear box.

The shear displacement of the lower box was controlled by a precise step-motor system. The shear displacement and shear force were monitored by a Linear Variable Differential 


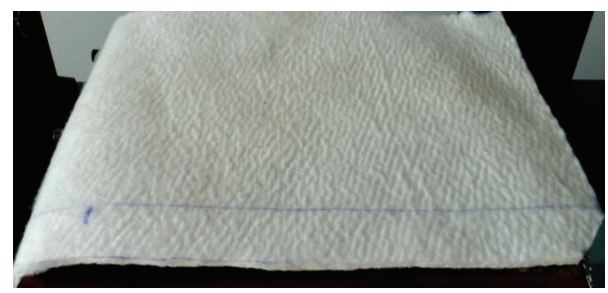

FIgURE 2: Composite geomembrane (CGM).

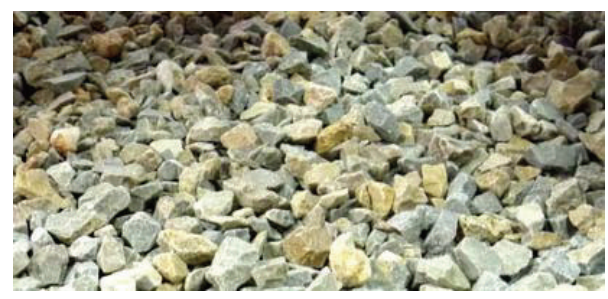

FIGURE 3: Crushed stones.

TABLE 1: Physical properties of crushed stones.

\begin{tabular}{lccccc}
\hline Size range $(\mathrm{mm})$ & $d_{50}(\mathrm{~mm})$ & $C_{u}$ & $C_{c}$ & $\rho_{d}\left(\mathrm{~g} / \mathrm{cm}^{3}\right)$ & $\Phi\left(^{\circ}\right)$ \\
\hline $5-20$ & 10 & 4.2 & 2.4 & 1.725 & 48 \\
\hline
\end{tabular}

Transducer (LVDT) and a load cell, respectively. A computerized data-acquisition system was installed to collect the displacement and shear stress data.

2.2. Materials. The CGM commonly used as surface barrier of rock-fill dam in China was chosen in the tests. The photograph of the CGM is shown in Figure 2. It consists of a $0.8 \mathrm{~mm}$ thick HDPE geomembrane laminated to a $400 \mathrm{~g} / \mathrm{m}^{2}$ polyethylene terephthalate (PET) needle punched nonwoven geotextile at both sides. Its ultimate tensile strength (ASTM D4595, 2005) in machine direction and cross-machine direction is $75.9 \mathrm{kN} / \mathrm{m}$ and $58.3 \mathrm{kN} / \mathrm{m}$, respectively.

The crushed stones used in the tests are shown in Figure 3. It is a type of coarse gravelly material crushed from fresh granite stones. The physical properties of crushed stones are presented in Table 1.

The PUR mixed crushed stones used in the tests is shown in Figure 4. It was casted by polyurethane adhesive mixed above-mentioned crushed stones with a quality ratio of $2.5 \%$. Its effective porosity and compressive modulus of elasticity are $32 \%$ and $8 \mathrm{GPa}$, respectively. By curing 2 days in standard curing box, the unconfined compressive strength and bending strength can reach $3.1 \mathrm{MPa}$ and $1.6 \mathrm{MPa}$, respectively.

2.3. Test Procedure. In the preparation stage, the CGM samples were cut into rectangles of $450 \times 300 \mathrm{~mm}$. The specimens of PUR mixed crushed stones were casted into $300 \times 300 \times$ $10 \mathrm{~mm}$ blocks at least 2 days in advance.

Standard Procedure B for soil and geosynthetic friction adopted from ASTM D-5321(2008) standard test method was used in this study. An iron block with a rough surface was placed in the lower box as a rigid substrate. Then CGM

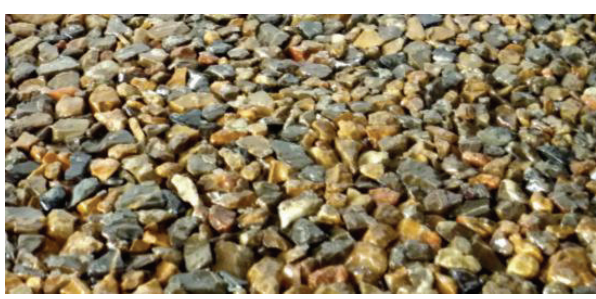

FIGURE 4: PUR mixed crushed stones.

specimen was glued to the top face of the rigid block. And the left end of CGM was fixed on the side of lower box with steel bar and screws. Then the crushed stones or precast PUR mixed crushed stones specimen was placed in the upper box. The bottom surface of the cushion should keep a good contact state with upper surface of CGM. For cushion of crushed stones, it was compacted by tamping to a desired relative density of $70 \%$.

In each series of tests, the normal stress was maintained at $25,50,75$, and $100 \mathrm{kPa}$, respectively. The shearing rate was kept at $1.0 \mathrm{~mm} / \mathrm{min}$. Every test was conducted until the applied shear force remains constant with increasing displacement or till shear displacement reaches $20 \mathrm{~mm}(1 / 15$ of the sample length) if shear force continuously increases with increasing displacement.

\section{Test Results}

3.1. Shear Stress-Shear Displacement Responses of Interfaces. The shear stress-shear displacement responses on the interfaces between CGM and two cushion materials under different normal loads are presented and discussed in this section.

The shear stress versus shear displacement curves of CGM-crushed stones interface are shown in Figure 5(a). The shear stresses increase rapidly as soon as shear displacements start and continue to increase to comparatively large shear displacement values. The test results show that no welldefined peak shear strength is observed for the CGM-crushed stones interface. An obvious stain-hardening characteristic of the shear stress-shear displacement response can be seen from the test results. It is different from geotextile-gravelly soil interface that exhibited evident strain-softening characteristics in literature [11]. The main reason could be the difference of surface texture and elasticity between CGM and geotextile.

The ultimate state of CGM surface after testing is shown in Figure 6. It can be seen that the filament structures on the surface were destroyed by the angular crushed stones. Many broken particles of the crushed stones had embedded in the surface of CGM. It is indicated that the interlocking exists between the angular-shaped gravels and geotextile at the upper side of CGM. It can also be observed that the increasing normal load results in increased interlocking. That may be the reason why the CGM-crushed stones interface shown significant hardening characteristics. A nonlinear hyperbolic relationship between the shear stress and shear displacement can be found. 


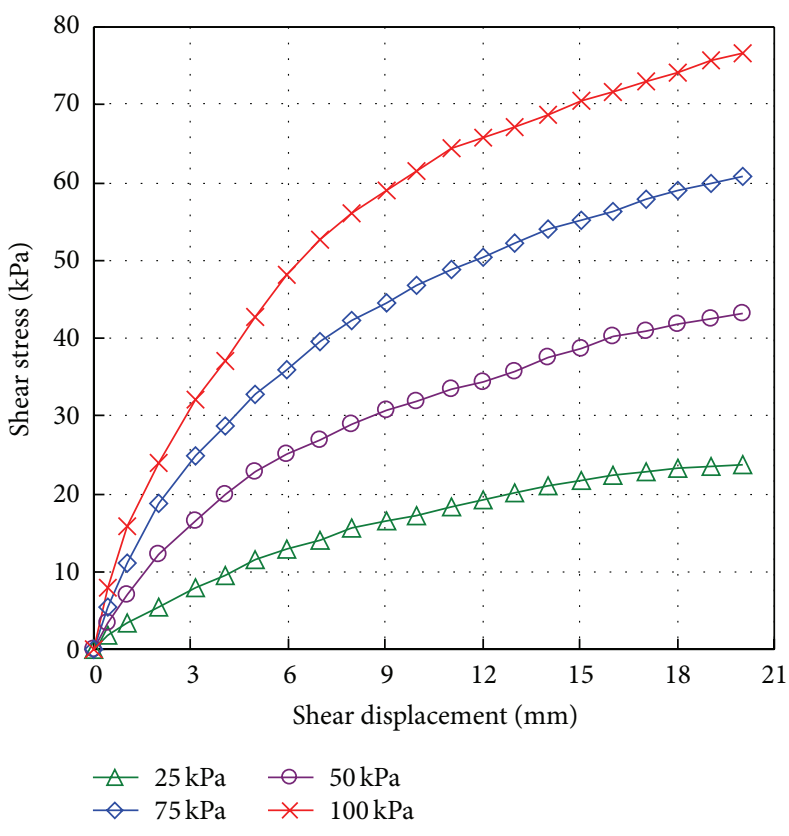

(a) CGM-crushed stones interface

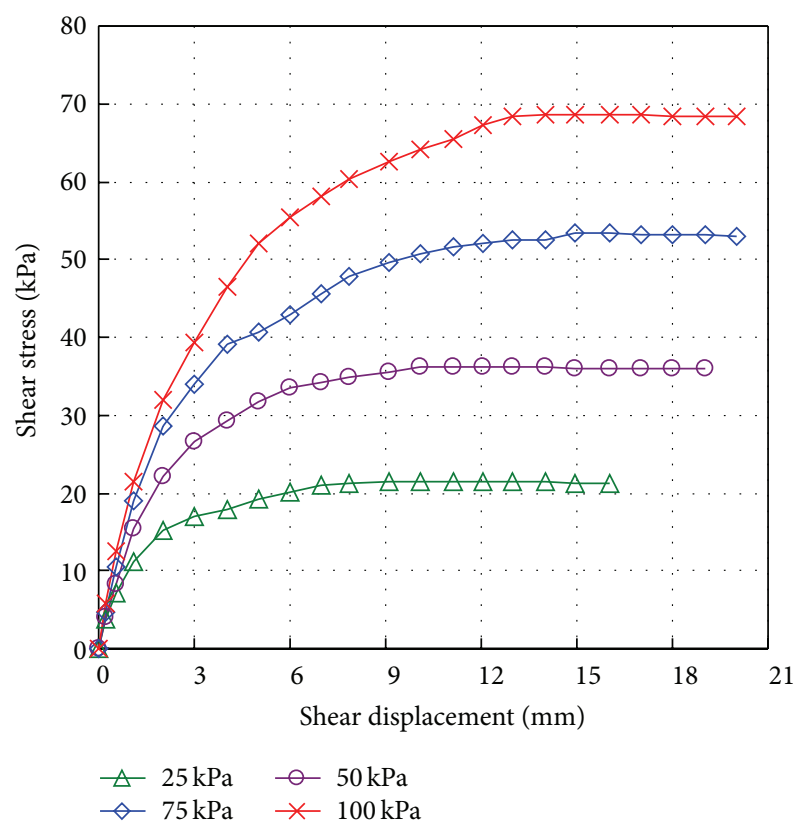

(b) CGM-PUR mixed crushed stones interface

FIGURE 5: Shear stress versus shear displacement of CGM-cushion interfaces.

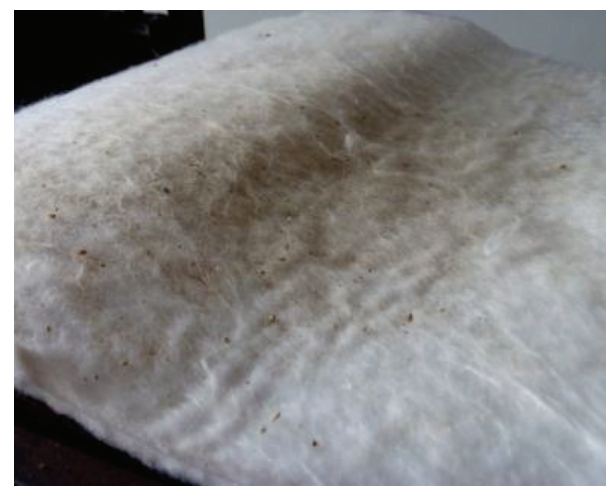

FIGURE 6: Ultimate surface state of CGM after testing.

The shear stress versus shear displacement curves of CGM-PUR mixed crushed stones interface under different normal loads are shown in Figure 5(b). A different shear stress-displacement response can be observed compared with the GM-crushed stones interface. An initial increase in shear stress with increasing displacement can be seen in the shear stress-displacement curves. When the shear stress reaches peak shear strength, the plastic failure begins with the increasing of shear displacement. The interface shows a failure mode of elastic perfect-plastic and sliding along the shear plane.

The ultimate surface state of CGM and PUR mixed crushed stones after testing is shown in Figure 7. It can be seen that the filament structure of CGM surface realigned along the shearing direction through frictional interaction.
Some filament had dropped off from the surface of CGM and embedded into the slits of PUR mixed crushed stones. It is indicated that a slippage failure had occurred on the interface for large shear displacement. It also can be found that a nonlinear-elastic perfect-plastic relationship can be used to express the complete shear stress and shear displacement relationship from the curves in Figure 5(b).

3.2. Peak Shear Strength of Interfaces. The variations of the peak shear stress with normal stress for the two interfaces are shown in Figure 8. The results show an apparent adhesion on the peak shear strength of the two interfaces. It is observed that the peak shear stresses increase with increase of normal stress. The shear strength of CGM-crushed stones interface is always higher than that of CGM-PUR mixed crushed stones interface under different normal loads. The shear strength of the two interfaces can be expressed as a function of normal stress by Mohr-Coulomb criteria.

For CGM-crushed stones interface, a friction angle of $35.2^{\circ}$ and an adhesion intercepts of $6.93 \mathrm{kPa}$ can be found from the linear regression fits of the test results. And lower shear strength with friction angle of $32.3^{\circ}$ and adhesion intercepts of $5.38 \mathrm{kPa}$ can be found for the CGM-PUR mixed crushed stones interface. It is supposed that the adhesive film wrapping the surface of gravels had decreased the roughness of the crushed stones. Besides, the measured shear strength of CGM-crushed stones interface is composed of the friction between gravel and geotextile surface and some interlocking resistance between gravel particles. Therefore, the shear strength for CGM-crushed stones interface is larger than that for CGM-PUR mixed crushed stones interface. 


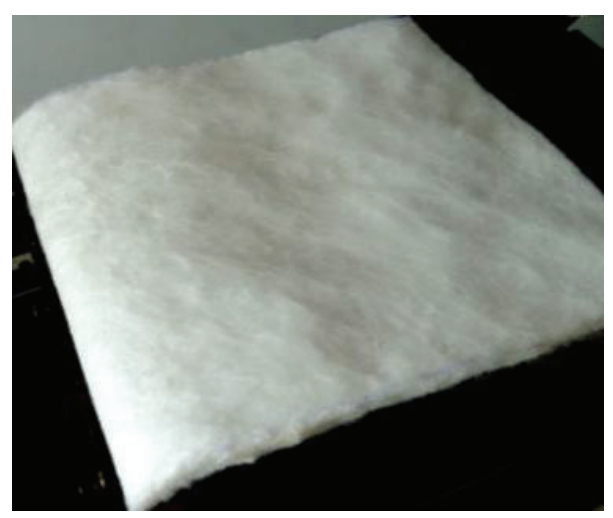

(a)

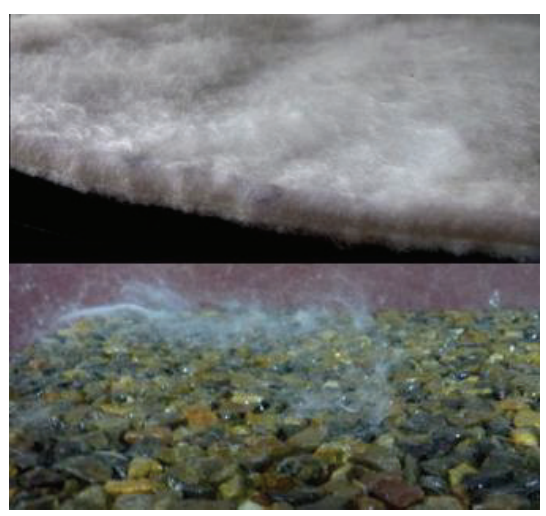

(b)

FIGURE 7: Ultimate surface state of CGM and PUR mixed crushed stones after testing.

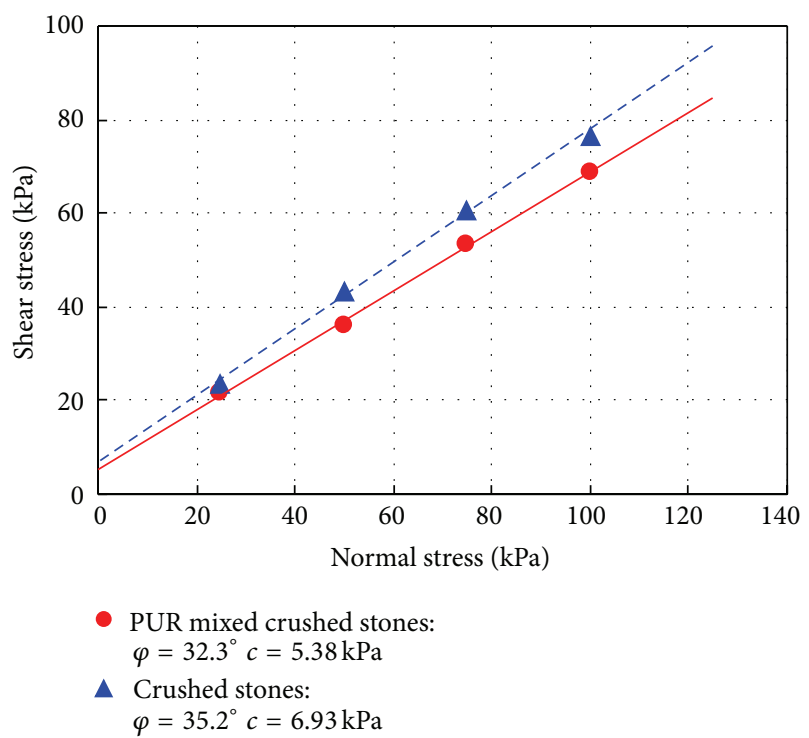

FIGURE 8: Shear strength envelops of two interfaces.

\section{Numerical Modeling of Interface Behavior}

Based on the results of direct shear tests, the mechanical behavior of the CGM-crushed stones interface can be described by a nonlinear hyperbolic model [15], namely, the nonlinear-elastic stage of the nonlinear-elastic perfectly plastic interface model (Figure 9). And for the CGM-PUR mixed crushed stones interface, a nonlinear-elastic perfectly plastic interface constitutive model that combines the nonlinear hyperbolic model (nonlinear-elastic stage) with the MohrCoulomb plastic failure envelope (perfectly plastic stage) can be used to describe the mechanical behavior.

\subsection{Nonlinear-Elastic Perfectly Plastic Constitutive Model of Interface}

4.1.1. Nonlinear-Elastic Stage. Before shear stress reaches peak shear strength, the relationship between shear stress and

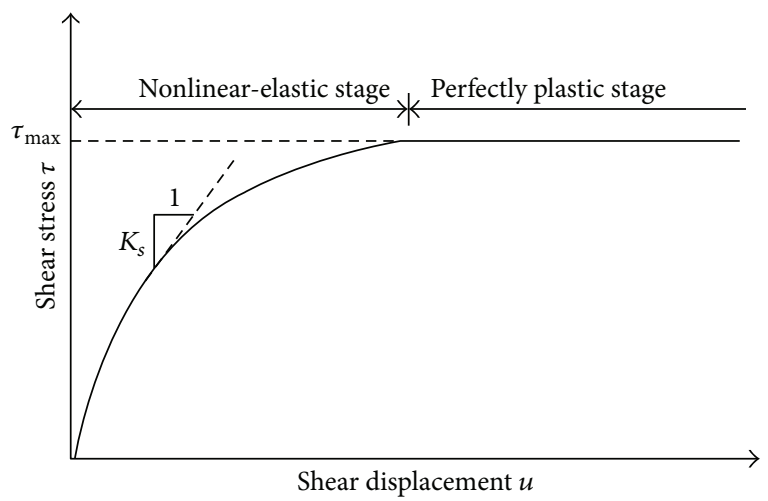

FIGURE 9: Nonlinear-elastic perfectly plastic model of interface.

shear displacement of the interface can typically be modeled by a hyperbolic equation:

$$
\tau=\frac{u}{a+b u}
$$

where $u$ is shear displacement of interface.

The parameters $a$ and $b$ can be expressed as

$$
\begin{gathered}
a=\frac{1}{k_{1} \gamma_{w}\left(\sigma_{n} / \mathrm{Pa}\right)^{n}}, \\
b=\frac{R_{f}}{\sigma_{n} \tan \phi+c},
\end{gathered}
$$

where $\gamma_{w}$ is the unit weight of water; $\sigma_{n}$ is the normal effective stress of the interface; $\mathrm{Pa}$ is the atmospheric pressure; $\tau$ is the shear stress; $c$ is the cohesion of the interface; $\phi$ is the friction angle of interface; $k_{1}, n$, and $R_{f}$ are the nonlinear parameters that can be derived from interface direct shear tests.

By combining the three equations above, the tangent modulus of the shear stress-displacement curve of the interface (shear stiffness) $k_{s}$ can be expressed as follows [16]:

$$
k_{s}=K_{1} \gamma_{w}\left(\frac{\sigma_{n}}{\mathrm{~Pa}}\right)^{n}\left[1-R_{f} \frac{\tau}{c+\sigma_{n} \tan \phi}\right]^{2} .
$$




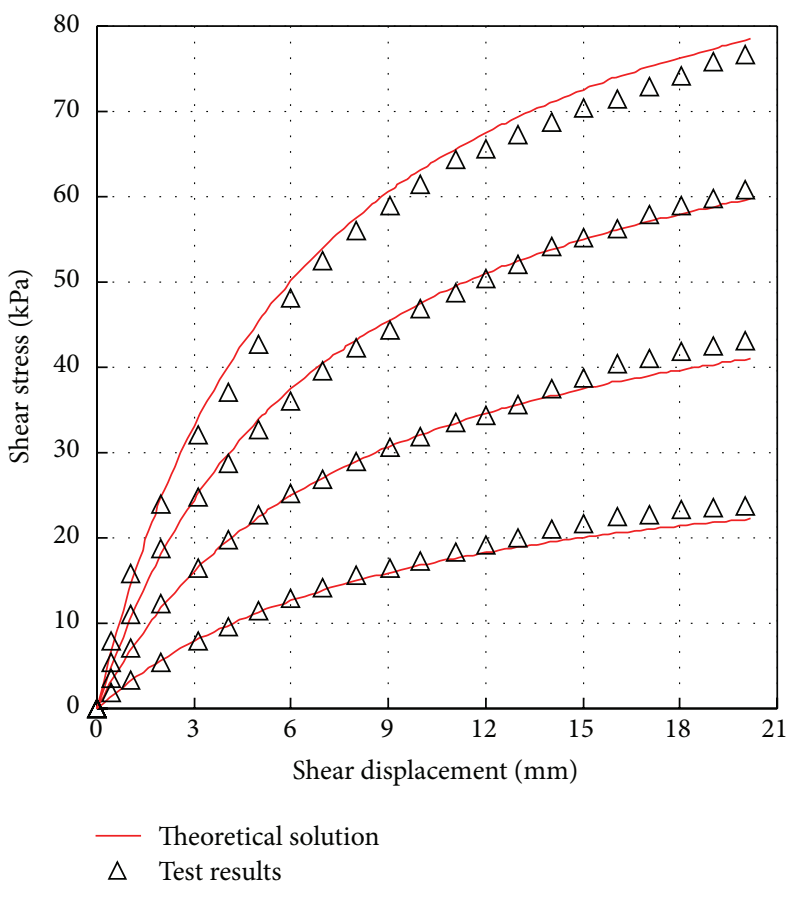

(a) CGM-crushed stones interface

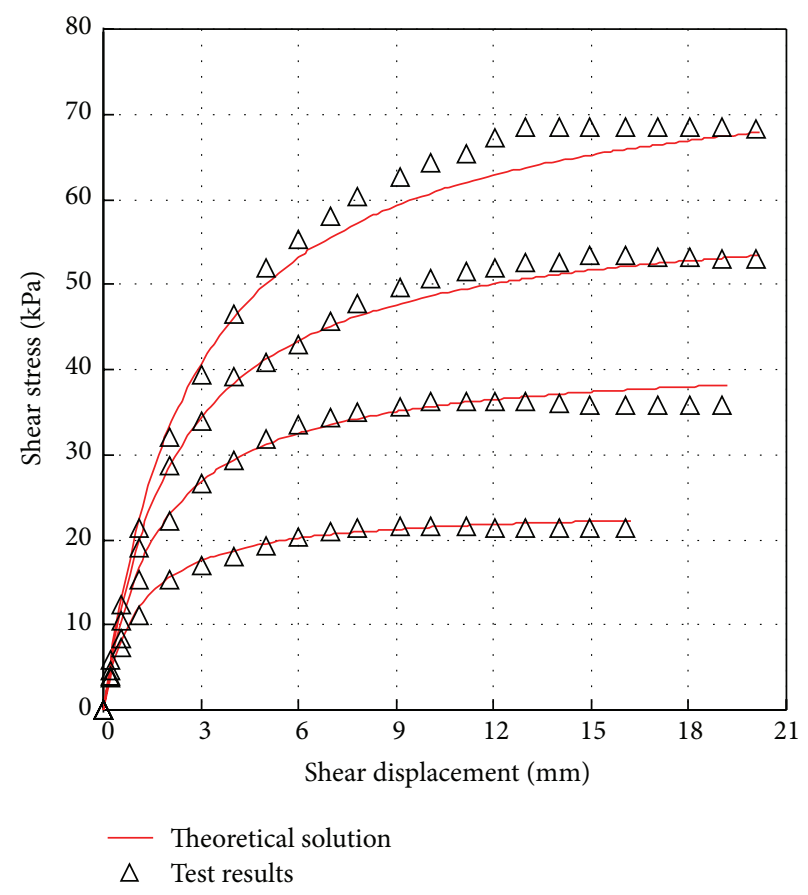

(b) CGM-PUR mixed crushed stones interface

Figure 10: Comparison of test data with fitting curves of interface model.

TABLE 2: Fitting parameters of two interfaces by nonlinear-elastic perfectly plastic model.

\begin{tabular}{lcccc}
\hline Parameters & $K$ & $n$ & $R_{f}$ & $c(\mathrm{~Pa})$ \\
\hline GM-crushed stones interface & 1624 & 1.12 & 0.75 & 6930 \\
GM-PUR mixed crushed stones interface & 2871 & 0.185 & 0.893 & 35.2 \\
\hline
\end{tabular}

4.1.2. Perfectly Plastic Stage. When shear stress reaches the peak shear strength of interface, the plastic failure occurs with the increase of shear displacement. The shear strength envelope in the postpeak stage is expressed by Mohr-Coulomb failure criteria:

$$
\tau=\tau_{\max }=c+\sigma_{n} \tan \phi,
$$

where $\tau_{\max }$ is the shear strength of interface; $c$ is the cohesion of interface; $\phi$ is the friction angle of interface.

4.2. Parameters of CGM-Cushion Interface Model. The fitting curves of shear stress versus shear displacement from the test results of the two interfaces using nonlinear-elastic perfectly plastic interface model are shown in Figure 10. The fitting parameters for the two interface models are given in Table 2. The comparisons between theoretical solutions calculated by the model and test results show good agreement under different normal loads.

4.3. Numerical Implementation of Interface Constitutive Model. In order to simulate the mechanical behaviors of CGM-cushion interfaces, the nonlinear-elastic perfectly plastic interface model was incorporated into the built-in Geogrid element of FLAC ${ }^{3 \mathrm{D}}$ procedure by user-defined FISH program. The Geogrid element in $\mathrm{FLAC}^{3 \mathrm{D}}$ provides interface model that is characterized by Coulomb sliding and shear bonding. Interfaces of Geogrid element have the properties of friction, cohesion, shear stiffness, and shear bond strength [17]. But the Geogrid element in FLAC ${ }^{3 \mathrm{D}}$ can only simulate the interface with linear elastic characteristics. It cannot be used to simulate geosynthetic-soil interfaces which are characterized by the nonlinear behaviors. So the Geogrid element in FLAC $^{3 \mathrm{D}}$ should be improved to simulate the CGM-cushion interface behaviors by user-defined fish program.

The detailed program flow chart of implementation of CGM-cushion interface model in FLAC $^{3 \mathrm{D}}$ procedure is shown in Figure 11.

As shown in Figure 11, at every calculation step, the program first reads the normal effective stress and shear stress of the three interface nodes for every Geogrid element. The resultant interface normal stress and shear stress of the Geogrid element are calculated according to the node variables. Then the stiffness of the interface was calculated according to the resultant interface variables by (3). The shear stiffness is inputted into the Geogrid element using fish functions. Then, the calculated new parameters for each Geogrid element were inputted to carry out the calculation of the next step. In this way, the program continuously circulated until the cycle for all Geogrid elements has been completed. 


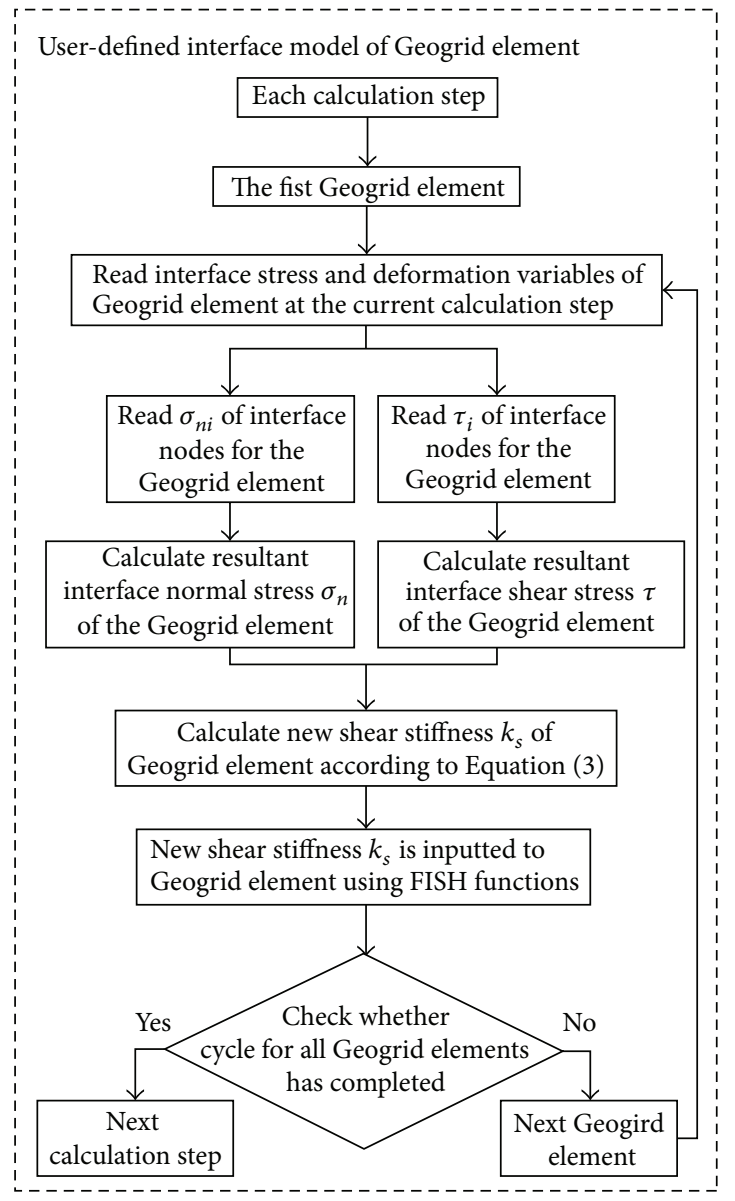

FIGURE 11: Program flow chart of user-defined interface model of Geogrid element.



FIGURE 12: Grid of numerical model for direct shear test.

4.4. Verification of Interface Constitutive Model. In order to verify the effectiveness of the imbedded interface model, a simple numerical example is chosen to model the direct shear test results of CGM-cushion interfaces. As shown in Figure 12, the numerical model of the test is composed of two parts. The upper part is a shear box with cushion materials in it; the lower one is a rigid block where the geomembrane is glued at the top. The numerical model of cushion is a 300 $\times 300 \times 100 \mathrm{~mm}$ cuboid which is simulated using hexahedral brick elements. The numerical model of rigid block is a $300 \times 350 \times 100 \mathrm{~mm}$ cuboid which is also simulated using hexahedral brick elements. The Geogrid element is used to simulate the GCM. The newly imbedded interface model is used to simulate the CGM-cushion interface behaviors. The boundary conditions correspond to roller boundaries on both sides ( $y$-direction and $x$-direction) and to fixed displacements in the $y$ - and $z$-direction at the model base.

In order to compare the numerical results with theoretical solutions and test results, a linear elastic model was employed for the cushions in the upper box as well as the rigid block in the lower box. Gravity forces of cushions and rigid block were not considered during the numerical modeling. Parameters in Table 2 were used in numerical model. According to the typical procedures for direct shear test, a constant normal pressure was applied on the top surface of the cushion. Then, the displacements and velocities of all elements were reset to zero. A fixed shear velocity of $1 \times 10^{-5} \mathrm{~m} /$ (time step) was applied to all the elements of the lower box to simulate the actual shearing rate of $1 \mathrm{~mm} / \mathrm{min}$. That led to a shear displacement on the interface between the upper cushion and the lower CGM. Four numerical direct shear tests were conducted with constant normal pressures of $25 \mathrm{kPa}, 50 \mathrm{kPa}$, $75 \mathrm{kPa}$, and $100 \mathrm{kPa}$, respectively.

The numerical computed results of the average shear stress versus shear displacement curves of two interfaces and 


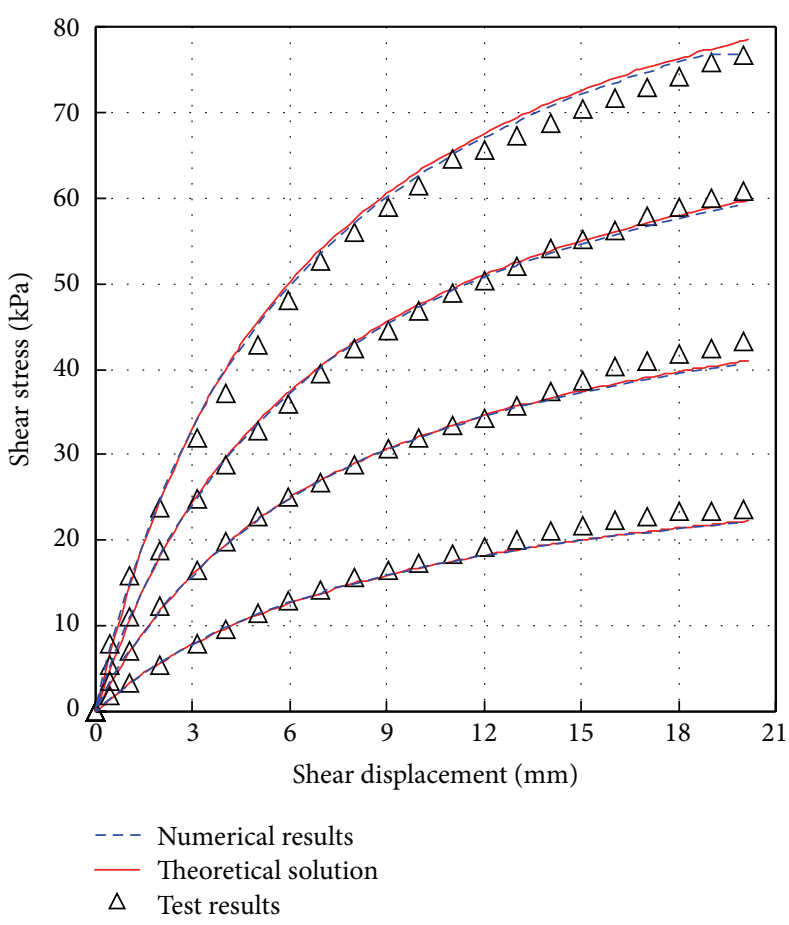

(a) CGM-crushed stones interface

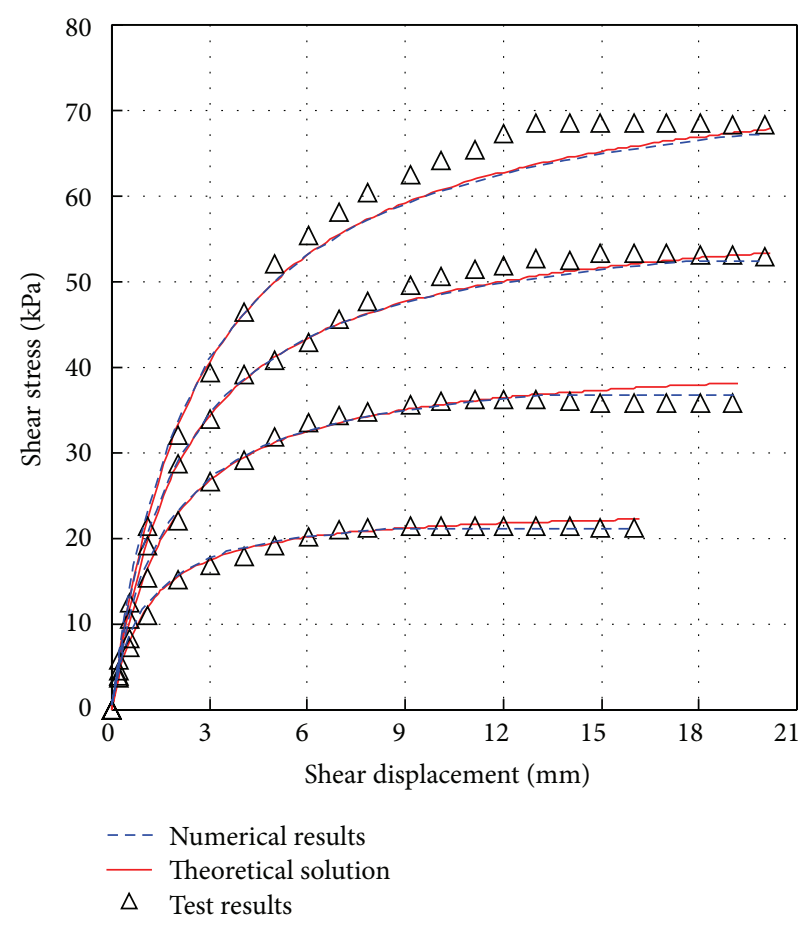

(b) CGM-PUR mixed crushed stones interface

FIGURE 13: Comparison of numerical results with test results and theoretical solution of interfaces.

the comparison with test results and theoretical solution are shown in Figure 13. It is obvious that the numerical results are very close to the theoretical solutions calculated by (1)(4) using the same parameters. Both the numerical and theoretical solutions show good agreements with test results for the two interfaces. Figure 13 illustrates that the implemented interface model in Geogrid element of FLAC ${ }^{3 \mathrm{D}}$ is capable of modeling the nonlinear-elastic and perfectly plastic behavior of interface between CGM and two permeable cushions.

\section{Conclusions}

Based on the present study, the following conclusions can be drawn for the interface behaviors of CGM and two different permeable cushions.

(i) Shear stress versus shear displacement curves of interfaces between CGM and two cushions have shown different features. The nonlinear and strain hardening characteristics can be found for CGMcrushed stones interface. Nonlinear and perfectly plastic failure characteristics were found for CGMPUR mixed crushed stones interface.

(ii) The peak shear strength of the two interfaces can be expressed as a function of normal stress by MohrCoulomb criteria. The peak shear strength of CGMcrushed stones interface is always higher than CGMPUR mixed crushed stones interface under different normal loads. Both lower friction angle and adhesion intercepts were observed for the CGM-PUR mixed crushed stones interface.

(iii) By fitting test data, the nonlinear hyperbolic model and nonlinear-elastic perfectly plastic interface model can be used to predict the mechanical behaviors of the two interfaces, respectively. The interface model of CGM-cushions was implemented into the Geogrid element of FLAC ${ }^{3 \mathrm{D}}$. By simulation of the interface direct shear tests, the incorporated interface model was proved correct and cable of modeling the mechanical behaviors of CGM-permeable cushion interfaces.

\section{Conflict of Interests}

The authors declare that there is no conflict of interests regarding the publication of this paper.

\section{Acknowledgments}

The research described in this paper was financially supported by the Natural Science Foundation of China (nos. 51409083 and 51379069) and Jiangsu Planned Projects for Postdoctoral Research Funds (no. 1302010A). The authors would like to thank the anonymous referees whose comments helped to improve the presentation of this paper. 


\section{References}

[1] The International Commission on Large Dams (ICOLD), Bulletin 135. Geomembrane Sealing Systems for Dams-Design Principles and Return of Experience, Paris, France, 2010.

[2] H. M. Wu, Research on key problems in geomembrane surface barrier of Rock-fill dam on thick riverbed alluvial deposit [Ph.D. dissertation], Hohai University, Nanjing, China, 2013, (Chinese).

[3] Ministry of Water Resources of the People's Republic of China, "Standard for applications of geosynthetics in hydraulic and hydro-power engineering," Resources of the People's Republic of China SL/T225-98, China Water Power Press, Beijing, China, 1998, (Chinese).

[4] H. M. Wu, Y. M. Shu, X. L. Zhang, X. L. Man, and X. X. Liu, "A geomembrane surface barrier system and its construction method of rock-fill dam on thick riverbed alluvial deposit," Patent, China, 201310592978.7, 2013 (Chinese).

[5] C.-N. Liu and R. B. Gilbert, "Simplified method for estimating geosynthetic loads in landfill liner side slopes during filling," Geosynthetics International, vol. 10, no. 1, pp. 24-33, 2003.

[6] S.-A. Tan, N. Muhammad, and G.-P. Karunaratne, "Adhesion at jute geotextile/clay slurry interface," Soils and Foundations, vol. 35, no. 3, pp. 15-22, 1995.

[7] M. Salehi, "Studies on geotextile/soil interface shear behavior," in Proceedings of the 4th International Symposium on Landmarks in Earth Reinforcement, Fukuoka, Japan, November 2001.

[8] D. Esmaili, K. Hatami, and G. A. Miller, "Influence of matric suction on geotextile reinforcement-marginal soil interface strength," Geotextiles and Geomembranes, vol. 42, no. 2, pp. 139153, 2014.

[9] K. M. Lee and V. R. Manjunath, "Soil-geotextile interface friction by direct shear tests," Canadian Geotechnical Journal, vol. 37, no. 1, pp. 238-252, 2000.

[10] S. Anubhav and P. K. Basudhar, "Interface behavior of woven geotextile with rounded and angular particle sand," Journal of Materials in Civil Engineering, vol. 25, no. 12, pp. 1970-1974, 2013.

[11] G. Zhang and J.-M. Zhang, "Large-scale monotonic and cyclic tests of interface between geotextile and gravelly soil," Soils and Foundations, vol. 49, no. 1, pp. 75-84, 2009.

[12] G. Zhang, L. Wang, and J. M. Zhang, "Monotonic and cyclic modeling of interface between geotextile and gravelly soil," International Journal for Numerical and Analytical Methods in Geomechanics, vol. 34, no. 13, pp. 1346-1361, 2010.

[13] C. Hsieh and M.-W. Hsieh, "Load plate rigidity and scale effects on the frictional behavior of sand/geomembrane interfaces," Geotextiles and Geomembranes, vol. 21, no. 1, pp. 25-47, 2003.

[14] ASTM, "Standard test method for determining the coefficient of soil and geosynthetic or geosynthetic and geosynthetic friction by direct shear method," Tech. Rep. D5321, ASTM, Philadelphia, Pa, USA, 2008.

[15] G. W. Clough and J. M. Duncan, "Finite element analyses of retaining wall behavior," Journal of the Soil Mechanics and Foundations Division, vol. 97, no. 12, pp. 1657-1673, 1971.

[16] J. M. Duncan and C. Y. Chan, "Nonlinear analysis of stress and strain in soils," Journal of the Soil Mechanics and Foundations Division, vol. 96, no. 5, pp. 1629-1653, 1970.

[17] Itasca Consulting Group, FLAC 3D (Fast Lagrangian Analysis of Continua in Three Dimensions), Version 3.0, 2005. 

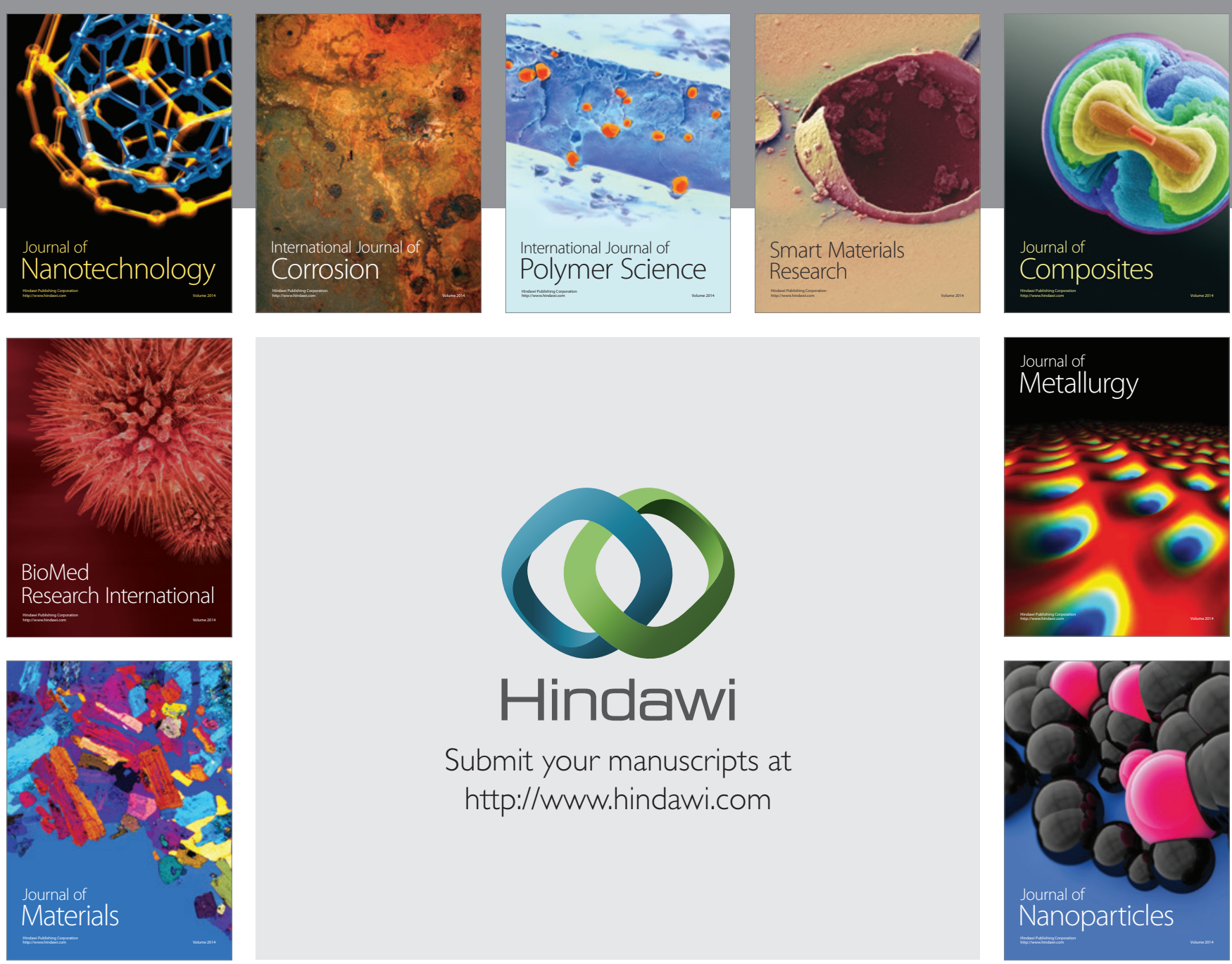

Submit your manuscripts at http://www.hindawi.com
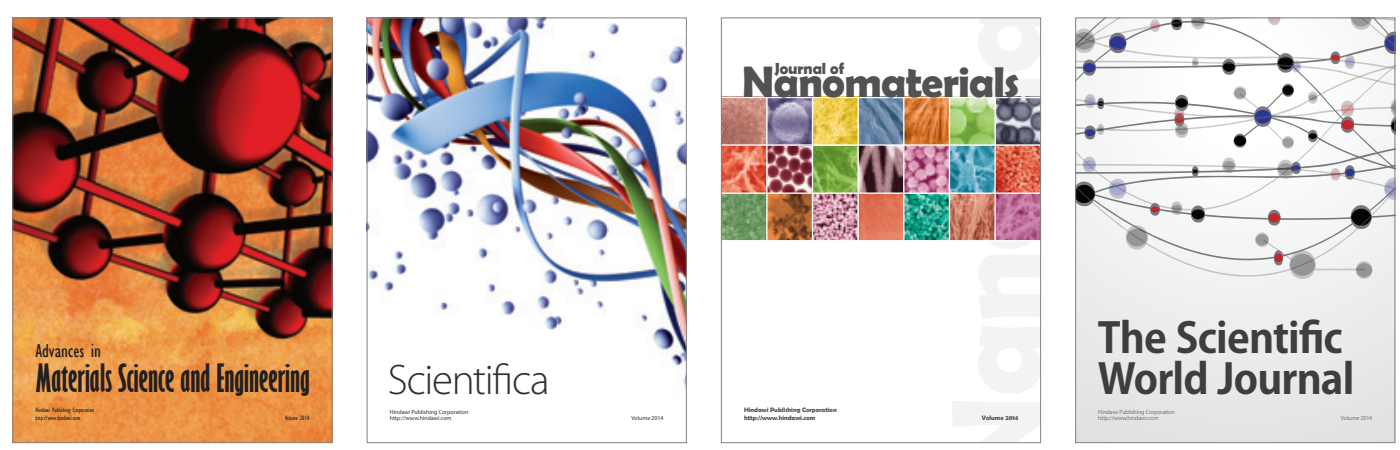

\section{The Scientific World Journal}
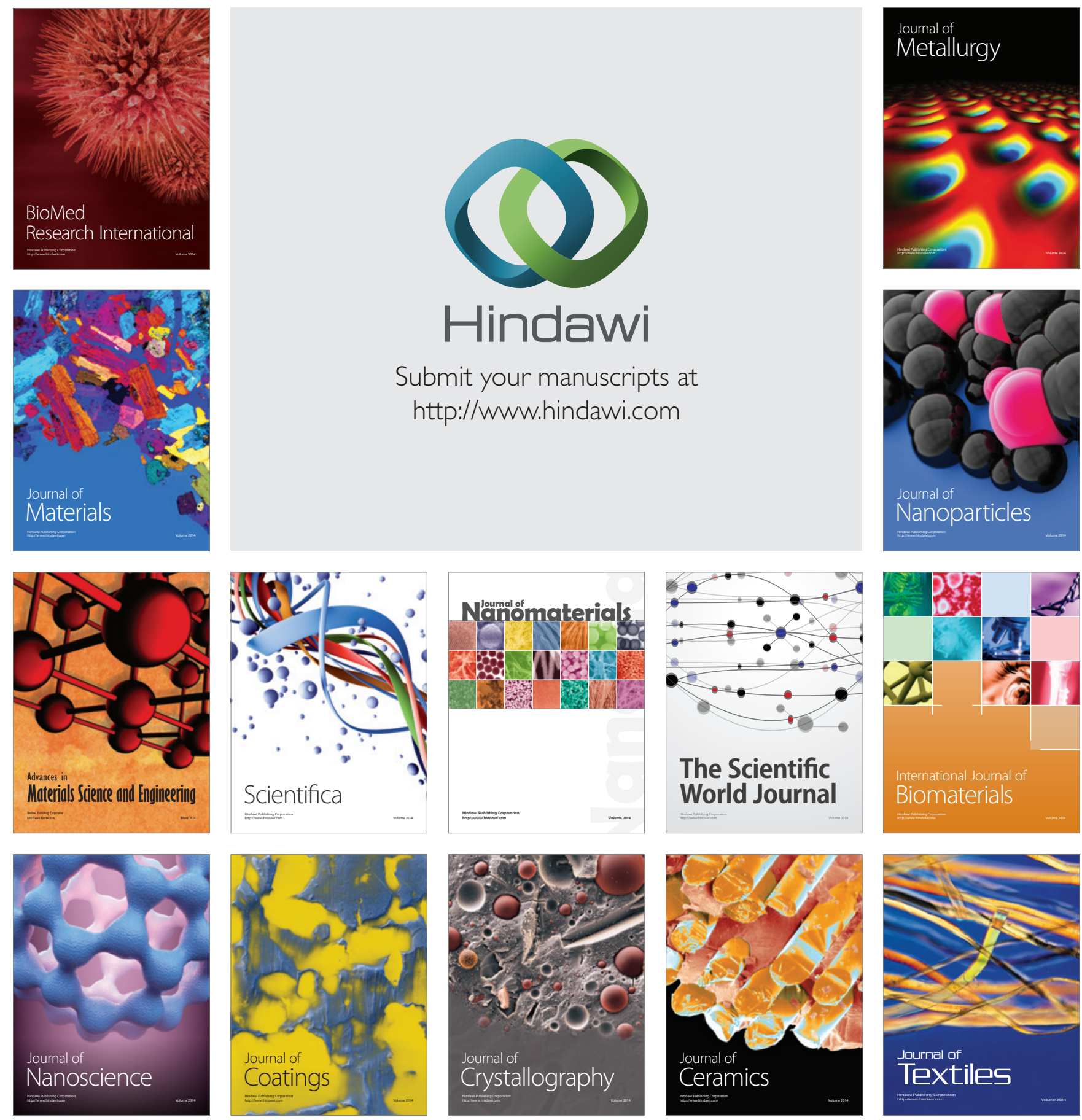